Research Article

\title{
Experimentally Determined Solute Mixing under Laminar and Transitional Flows at Junctions in Water Distribution Systems
}

\author{
Yu Shao $\left(\mathbb{D},{ }^{1}\right.$ Lei Zhao, ${ }^{2}$ Y. Jeffrey Yang, ${ }^{3}$ Tuqiao Zhang, ${ }^{4}$ and Miaomiao Ye ${ }^{5}$ \\ ${ }^{1}$ Associate Professor, Department of Civil Engineering, Zhejiang University, Hangzhou 310058, China \\ ${ }^{2}$ M.S. Student, Department of Civil Engineering, Zhejiang University, Hangzhou 310058, China \\ ${ }^{3}$ Senior Scientist and Advisor, U.S.EPA, Office of Research and Development, ORISE Fellowship, 26 W. Martin Luther King Dr., \\ Cincinnati, OH 45268, USA \\ ${ }^{4}$ Professor, Department of Civil Engineering, Zhejiang University, Hangzhou 310058, China \\ ${ }^{5}$ Associate Professor, Department of Civil Engineering, Zhejiang University, Hangzhou 310058, China
}

Correspondence should be addressed to Miaomiao Ye; yemiao008@zju.edu.cn

Received 3 November 2018; Revised 14 March 2019; Accepted 26 March 2019; Published 15 April 2019

Academic Editor: Daniele Baraldi

Copyright ( 92019 Yu Shao et al. This is an open access article distributed under the Creative Commons Attribution License, which permits unrestricted use, distribution, and reproduction in any medium, provided the original work is properly cited.

The water quality model in water distribution systems adopted in EPANET and other commercial simulation programs assumed perfect mixing of solute at pipe junctions. However, imperfect solute mixing at pipe junctions at turbulent flow has been reported. Yet, the mixing under laminar and transitional flow is rarely reported and thus is the focus of experimental study reported here. The experimental results show that the average Reynolds number and the outflows Reynolds number ratio controls degrees of the mixing at the pipe junctions. For cross junctions, the mixing degree is a function of the average Reynolds number in three regions; each has different mixing mechanisms and mathematical relationship. For double-Tee junctions, the dimensionless connecting pipe length plays a more important role than the Reynolds number ratios of outflows and average Reynolds number on mixing because a longer connecting pipe length gives more mixing space and time for the water flow mixing.

\section{Introduction}

Drinking water distribution network modeling using EPANET program [1] or EPANET Multi-Species Extension is widely used to predict the fate and transport of disinfectant residues and contaminants [2], the optimization of water quality monitoring sensors, optimal pump operation, and valve control for water quality purpose [3], and the determination of pollutant source. EPANET and those adopting the core simulation models assume perfect mixing of solutes in water parcels at pipe junctions [4]. Later, using numerical and experimental studies, Austin et al. [5] and Choi et al. [6] found that the complete mixing assumption may underestimate substance concentration leading to a large simulation error. Similarly, Ho et al. [7], Choi [8], and Mckenna et al. [9] found that the degree of mixing was much lower than that of complete mixing at pipe cross junctions. When studying the effects of Reynolds numbers on the amount of mixing, Austin et al. [10] did not find any effect of
Reynolds numbers on mixing at $\operatorname{Re}>10000$. At the same time, Romero-Gomez et al. [11] used numerical simulations to find that the main factor influencing the degree of solute mixing at high Reynolds numbers is the Reynolds number ratio rather than the Reynolds number itself.

Notably, these previous studies were focused on turbulent flow of the large Reynolds number (e.g., Re > 10000). $\mathrm{Yu}$ et al. [12] investigated the solute mixing at cross junctions and found that the inlet Reynolds number ratio was the most important factor affecting the mixing, followed by the pipe diameter ratio and the outlet Reynolds number ratio. Yu et al. [13] studied the solute mixing at double-Tee junctions and found that the mixing at doubleTee junctions is better than that at cross junctions. They also found that the joint with a large connecting pipe length $(L)$ has a more complete mixing than the one with a small connecting pipe length. Shao et al. [14] further used computational fluid modeling and solute mixing to analyze the mixing at cross junction and double-Tee junction, from 
which they introduced dimensionless parameter of Reynolds ratios in pipe flows to quantify the degree of solute mixing. Yu et al. [15] studied the mixing characteristics of the double-Tee junction with different diameters and found that the larger the pipe diameter ratio is, the better the mixing degree is. Song et al. [16] conducted laboratory experiments to characterize solute mixing patterns at double-Tee and wye junctions.

Comparatively, the junction mixing of the laminar and transitional flow has not been thoroughly investigated, partially because of difficulties in controlling experimental conditions. Among several studies in literature, Austin et al. [10] found that different Reynolds number has the different mixing degree at cross junction when the Reynolds number is less than 10000. Choi et al. [6] also found that the Reynolds number had a certain effect on the solute mixing at doubleTee junctions at low Reynolds numbers $(\operatorname{Re}<10000)$. Although most pipe flows in WDSs are turbulent, a small part of pipe flows are in the laminar and transitional flow region in water distribution systems [17]. The importance of studying solute mixing of the laminar and transitional flow can be underestimated.

The purpose of this work is to explore the mixing behavior at cross junctions and double-Tee junctions at $\operatorname{Re}<10000$, especially the laminar and transitional flow. The paper is presented in detail as follows: first, the definition of the mixing parameters and experimental approach, followed by experimental observation and results; finally, some discussions and conclusions are presented.

\section{Methodology: Definitions and Experiments}

2.1. Mixing Parameters. A typical cross joint and double-Tee joint used in experiments are shown in Figure 1. The pipes with geographic notations were labeled as $\mathrm{W}$ (west inlet, tracer water with high concentration $C_{\mathrm{W}}$ ), $\mathrm{S}$ (south inlet, clean water with low concentration $C_{\mathrm{S}}$ ), $\mathrm{E}$ (east outlet, concentration $C_{\mathrm{E}}$ ), and $\mathrm{N}$ (north outlet, concentration $C_{\mathrm{N}}$ ). $D$ and $L / D$ were also defined as pipe diameter and dimensionless connecting pipe length. Romero-Gomez et al. [18] defined the dimensionless concentration $\left(C^{*}\right)$ to describe the degree of mixing:

$$
\begin{gathered}
C_{\mathrm{E}}^{*}=\frac{C_{\mathrm{E}}-C_{\mathrm{S}}}{C_{\mathrm{W}}-C_{\mathrm{S}}}, \\
C_{N}^{*}=\frac{C_{\mathrm{N}}-C_{\mathrm{S}}}{C_{\mathrm{W}}-C_{\mathrm{S}}},
\end{gathered}
$$

Where $C_{\mathrm{E}}^{*}$ and $C_{\mathrm{N}}^{*}$ are the dimensionless concentrations of east outlet and north outlet. $C_{\mathrm{N}}$ and $C_{\mathrm{E}}$ are the concentrations of east outlet and north outlet. When $C_{\mathrm{N}}^{*}=C_{\mathrm{E}}^{*}=0.5$, it means that the mixing at junction is complete.

The average Reynolds number is defined as

$$
\mathrm{Re}_{\mathrm{ave}}=\frac{\left(\mathrm{Re}_{\mathrm{S}}+\mathrm{Re}_{\mathrm{W}}+\mathrm{Re}_{\mathrm{E}}+\mathrm{Re}_{\mathrm{N}}\right)}{4} \text {. }
$$

The Reynolds number ratios of outlets $\left(\mathrm{Re}_{\mathrm{N} / \mathrm{E}}\right)$ are defined as

$$
\begin{aligned}
& \operatorname{Re}_{\mathrm{N} / \mathrm{E}}=\frac{\operatorname{Re}_{\mathrm{N}}}{\operatorname{Re}_{\mathrm{E}}} \\
& \operatorname{Re}_{\mathrm{W} / \mathrm{S}}=\frac{\operatorname{Re}_{\mathrm{W}}}{\operatorname{Re}_{\mathrm{S}}} .
\end{aligned}
$$

Based on the numerical research, Shao et al. [14] found that the flow field in the mixing zone is complicated (Figure 2(a)). The flow rate is unevenly distributed at the mixing interface. The mixing interface line keeps $45^{\circ}$ as shown in Figure 2(b). Therefore, the interaction time can be defined as

$$
T=\sum_{i \in L^{*}} \frac{l_{i}}{v_{i}},
$$

where $L^{*}$ is a collection of line segments of the mixing interface line. $l_{i}$ and $v_{i}$ are the length of line segment and the velocity at this segment, respectively. Since the velocity at the interface is difficult to be measured and calculated, a simplified indicator mixing time is used to replace $T$ :

$$
t=\frac{D}{v},
$$

where $D$ and $v$ are the diameter and the average velocity of pipes connected to the junction.

2.2. Experimental Approach. To better understand the mixing behavior, a set of experiments were conducted to research the influence of average Reynolds number, Reynolds number ratios of outflows $\left(\mathrm{Re}_{\mathrm{N} / \mathrm{E}}\right)$, and pipe diameter at cross junctions. The Reynolds numbers of the four pipes $\left(\mathrm{Re}_{\mathrm{S}}, \mathrm{Re}_{\mathrm{W}}, \mathrm{Re}_{\mathrm{N}}\right.$, and $\left.\mathrm{Re}_{\mathrm{E}}\right)$ in the experiments were controlled in the range from 500 to 7500 (laminar, transition or uncompleted turbulence, and turbulence flow), and the pipe diameters are DN16, DN25, DN32, and DN50. The experimental cases to investigate the influence of pipe diameters for cross junctions are presented in Table 1. The Reynolds numbers of four pipes are kept equal. To investigate the influence of Reynolds number ratios of outflows, the cross junction with diameter of DN25 is used, and the experimental cases are shown in Table 2. Experiments on doubleTee junctions were also carried out, and the cases are presented in Tables 3 and 4. Note that the experimental setup and approach were based on the work of [13]. Every experiment was repeated thrice to obtain the average results.

The percent mass fraction error (PMFE) is used to check the experimental accuracy [9], as shown below:

$$
\operatorname{PMFE}=\left(\frac{Q_{\mathrm{N}} C_{\mathrm{N}}^{*}+Q_{\mathrm{E}} C_{\mathrm{E}}^{*}}{Q_{\mathrm{W}}}-1\right) .
$$

The closer the absolute value of PMFE is to 0 , the more reliable the data are. Each experimental case was repeated thrice independently by turning off the power of experimental system. Most of the PMFE values are $-1 \% \sim 3 \%$, which indicate that the experimental errors are well controlled. 


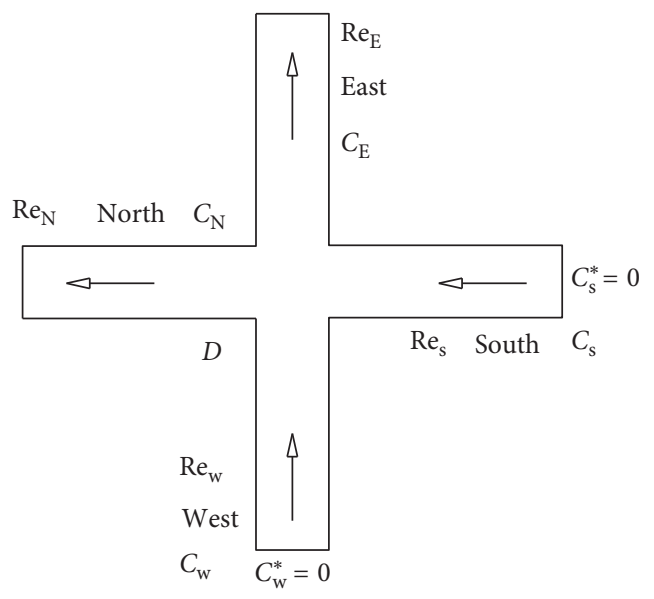

(a)

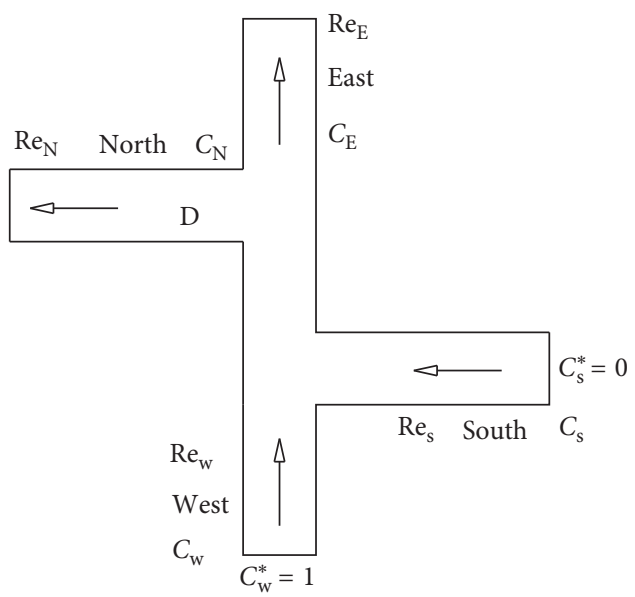

(b)

FIGURE 1: Hydraulic and water quality configurations of the junctions: (a) cross junction; (b) double-Tee junction.

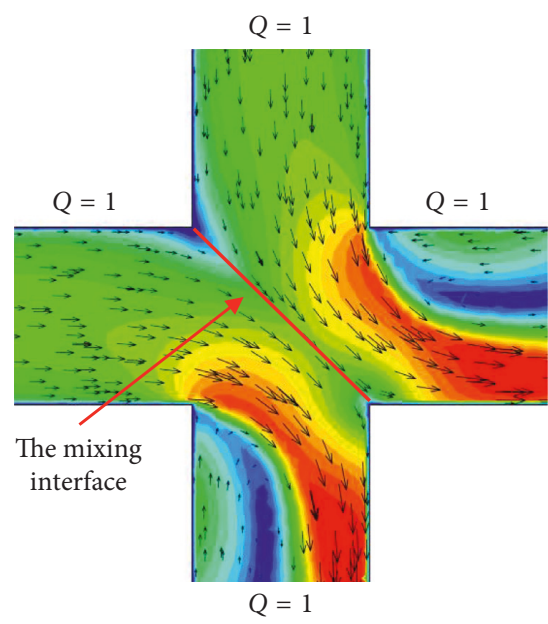

(a)

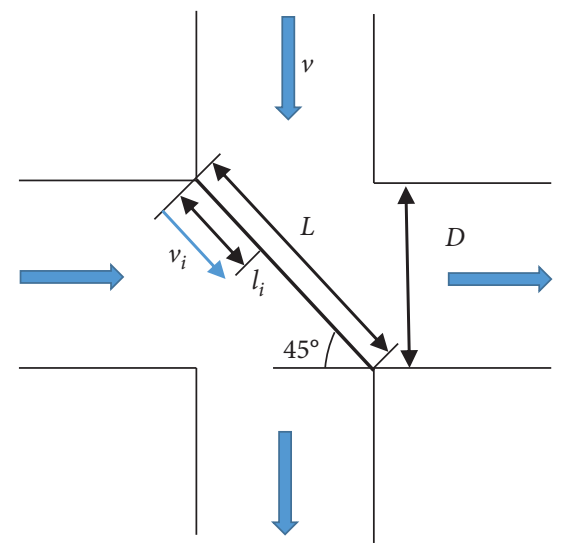

(b)

Figure 2: Flow velocity vectors and contours map for cross junction. Contours and arrows indicate the normalized flow velocity and direction.

TABLE 1: Summary of the experimental cases at cross junctions with $\operatorname{Re}_{\mathrm{W} / \mathrm{S}}=1$ and $\operatorname{Re}_{\mathrm{N} / \mathrm{E}}=1$.

\begin{tabular}{lc}
\hline $\begin{array}{l}\text { Pipe } \\
\text { diameter }\end{array}$ & $\mathrm{Re}_{\mathrm{ave}}$ \\
\hline DN16 & $500,750,1000,1250,1500,2000,2500,3000,3500$, \\
& $4000,4500,5500,6500,7500$ \\
DN25 & $500,750,1000,1250,1500,2000,2500,3000,3500$, \\
& $4000,4500,5500,6500,7500$ \\
DN32 & $500,750,1000,1250,1500,2000,2500,3000,3500$, \\
DN50 & 4000 \\
\hline
\end{tabular}

\section{Results and Discussion}

3.1. Influence of Reynolds Number on Cross Junction. The dimensionless concentrations of north outflow versus average Reynolds number are presented in Figure 3. The experiments were done at cross junctions of equal diameter for
TABLE 2: Summary of the experimental cases at cross junctions with different $\mathrm{Re}_{\mathrm{N} / \mathrm{E}}$ and $\mathrm{Re}_{\mathrm{W} / \mathrm{S}}=1$.

\begin{tabular}{lc}
\hline $\mathrm{Re}_{\text {ave }}$ & $\mathrm{Re}_{\mathrm{N} / \mathrm{E}}$ \\
\hline 500 & $0.25,0.5,0.67,1.0,1.5,2.0,4.0$ \\
1500 & $0.25,0.5,0.67,1.0,1.5,2.0,4.0$ \\
2500 & $0.25,0.5,0.67,1.0,1.5,2.0,4.0$ \\
4500 & $0.25,0.5,0.67,1.0,1.5,2.0,4.0$ \\
\hline
\end{tabular}

every 4 pipe legs. The incoming and outgoing flow rates are control to be equal, and therefore $\mathrm{Re}=\mathrm{Re}_{\mathrm{ave}}$ for this case. The pipe diameters of the cross junctions are DN16, DN25, DN32, and DN50. The experimental results of 4 junction sizes appear to have a similar trend. The data can be divided into 3 regions, $\operatorname{Re}<1500,1500<\operatorname{Re}<3000$, and $\operatorname{Re}>3000$, respectively. When $\operatorname{Re}<1500$, the degree of mixing decreases as the Reynolds number increases. The possible reason may be that the mixing time of the junction in this region is the primary factor to govern the mixing instead of 
TABLE 3: Summary of the experimental cases at double-Tee junctions with $\operatorname{Re}_{\mathrm{W} / \mathrm{S}}=1$ and $\operatorname{Re}_{\mathrm{N} / \mathrm{E}}=11$.

\begin{tabular}{lc}
\hline$L / D$ & $\mathrm{Re}_{\mathrm{ave}}$ \\
\hline 2.5 & $500,750,1000,1250,1500,2000,2500,3000,3500$, \\
& $4000,4500,5500,6500,7500$ \\
5.0 & $500,750,1000,1250,1500,2000,2500,3000$, \\
& $3500,4000,4500,5500,6500,7500$ \\
7.5 & $500,750,1000,1250,1500,2000,2500$, \\
10.0 & $3000,3500,4000$ \\
& $500,750,1000,1250,1500,2000,2500,3000$ \\
\hline
\end{tabular}

TABle 4: Summary of the experimental cases at double-Tee junctions with varied Reynolds number ratio at outlets $\left(\mathrm{Re}_{\mathrm{N} / \mathrm{E}}\right)$ and $\mathrm{Re}_{\mathrm{W} / \mathrm{E}}=1$.

\begin{tabular}{lcc}
\hline$L / D$ & $\mathrm{Re}_{\text {ave }}$ & $\mathrm{Re}_{\mathrm{N} / \mathrm{E}}$ \\
\hline 2.5 & 1500 & $0.25,0.5,0.67,1.0,1.5,2.0,4.0$ \\
5 & 2500 & $0.25,0.5,0.67,1.0,1.5,2.0,4.0$ \\
7.5 & 4500 & $0.25,0.5,0.67,1.0,1.5,2.0,4.0$ \\
10 & - & - \\
\hline
\end{tabular}

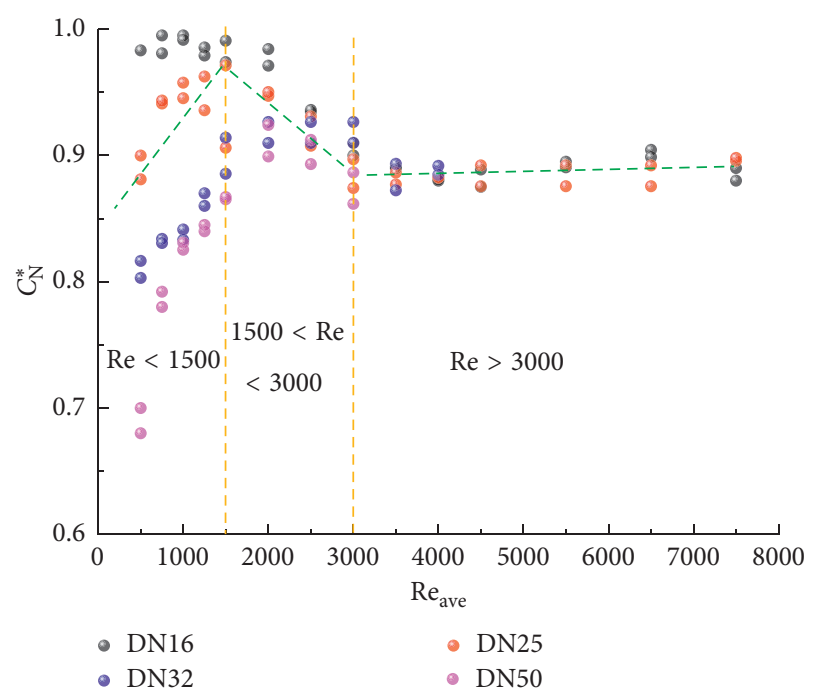

Figure 3: The dimensionless concentration of north outflow $C_{\mathrm{N}}^{*}$ versus average Reynolds number $\mathrm{Re}_{\mathrm{ave}}$.

disturbance diffusion. The flow rate increases and the mixing time decreases with the increase of the Reynolds number, the mixing becomes worse, and $C_{\mathrm{N}}^{*}$ reaches the peak near $\operatorname{Re}=1,500$. Figure 4 shows that mixing time dominates junction mixing under laminar flow especially in the junction with larger pipe diameter. When $1500<\operatorname{Re}<3000$, the mixing increases with the increase of the Reynolds number because the turbulence intensity is starting to be a determining factor on mixing, and the effect of mixing time weakens. It is logical that with the increase of the Reynolds number, the increased turbulence intensity enhances mixing. When $\operatorname{Re}>3000$, the effects of the mixing time and turbulence intensity on mixing are reduced further, until the mixing is not affected by them. Because the mixing time and turbulence intensity are two opposed factors, increasing the flow rate will enhance turbulence intensity but reduce mixing time. With the increase of Re, the above two factors will reach a balance, and then the change of the Reynolds number will not affect the junction mixing.

Laminar flow occurs when the calculated Reynolds number is less than 2300, and turbulent flow occurs when the Reynolds number calculation exceeds 4000 for pipe flows. In the actual mixing experiment, the flows are not well controlled to be very stable and the junction configuration breaks the laminar flow condition. The flow cannot be considered as laminar flow, and it is more like a jet stream. However, for the pipe diameters of DN16-DN50, the $C_{\mathrm{N}}^{*}$ reaches the peak at $\operatorname{Re}=1500$ and reaches stable value at $\operatorname{Re}>3000$. When $\operatorname{Re}=500$, the experimental data show a best mixing. Due to the limitation of flow measurement, the experiments with the Reynolds number less than 500 have not been done. Theoretically, the mixing time can be infinitely long if the flow velocity is close to zero, and then the molecular diffusion at the junction can also produce complete mixing.

To visually analyze the mixing phenomenon, a Plexiglass cross junction was used. As is shown in Figure 5, when $\operatorname{Re}_{\text {ave }}=500$, the mixing interface (the diagonal line of $45^{\circ}$ ) is blurry and the mixing happened in the entire junction space (Figure 5(a)). This observed phenomenon supports the good mixing result at the low Reynolds number. When Reave $=1500$, the $45^{\circ}$ mixing interface line is very clean (shown in Figure 5(c)), and the mixing only happened near the $45^{\circ}$ line. Obviously, the mixing is less sufficient than that of $\operatorname{Re}=500$. When $\operatorname{Re}=3,000$, the mixing gets better than $\mathrm{Re}=1500$ because of the effect of turbulent disturbance (Figure 5(d)), although, it is still worse than that of $R e=500$. The experimental concentration data (Figure 3) can fully support the mixing phenomenon seen in Figure 5.

3.2. Influence of Pipe Diameter on Cross Junction. The normalized north outlet concentration $C_{\mathrm{N}}^{*}$ versus pipe diameters $D$ under $\mathrm{Re}_{\mathrm{ave}}=500 \sim 5000$ is shown in Figure 6. Due to the limitation of the flow measurement, the experiment with a Reynolds number greater than 3000 at DN50 is not carried out. From Figure 6, it appears that at the same average Reynolds number, the larger the diameter, the better mixing happens at the cross junction. This is because at the same average Reynolds number, the larger the diameter is, the larger the mixing zone (the junction geometry space) is, and the lower flow rate leads to more mixing time. Therefore, mixing at cross junction of a large diameter is better than that of a small diameter. However, the effect of the diameter size is weakened with the increase of the pipe diameter. Especially, when $\operatorname{Re}>3000$, the size of the pipe diameter almost has no effect on the mixing.

3.3. Influence of Reynolds Number Ratios at Outlets $\left(R e_{N / E}\right)$ for Cross Junction. Romero-Gomez et al. [11] had studied the effect of Reynolds numbers ratios of outflows on cross junction at high Reynolds numbers. Our experimental results focused on $\operatorname{Re}<10000$ are shown in Figure 7. The experiment was done at cross junction with equal diameter 


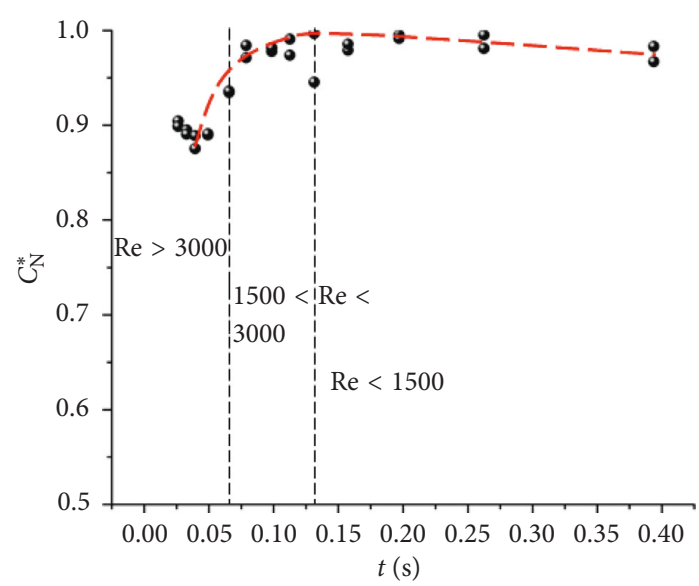

(a)

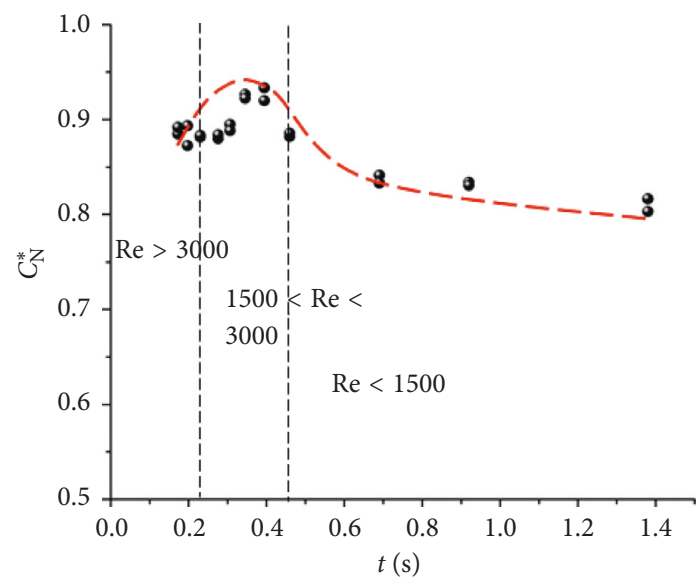

(c)

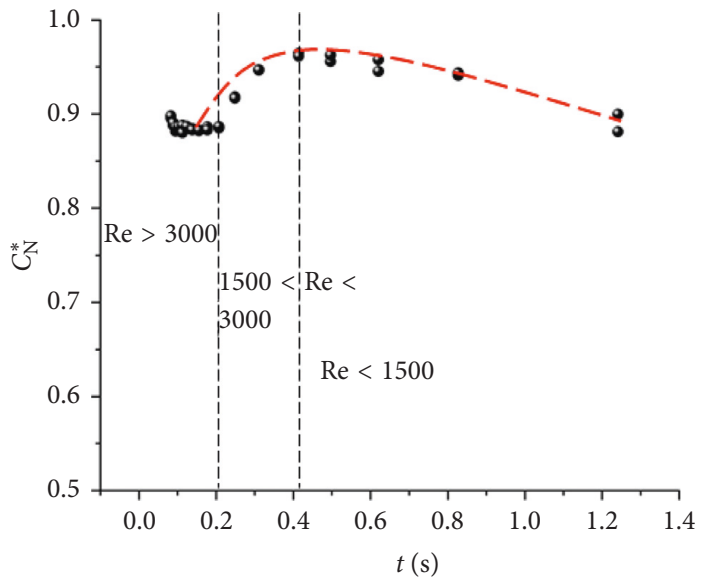

(b)

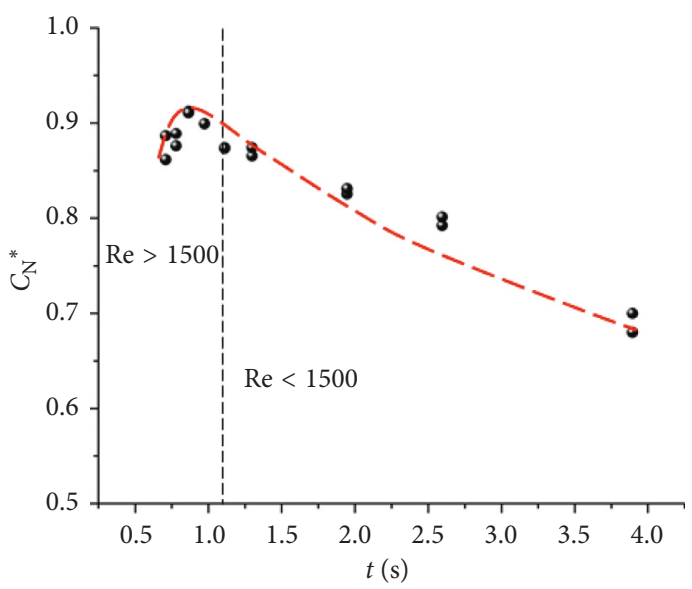

(d)

FIGURE 4: The dimensionless concentration of north outflow $C_{\mathrm{N}}^{*}$ versus mixing time $t$ : (a) DN16; (b) DN25; (c) DN32; (d) DN50.

of DN25. The flow rates of incoming south and west flows were set to be equal. The north and east outlet flow rates were changed to follow $0.25<\mathrm{Re}_{\mathrm{N} / \mathrm{E}}<4.0$; however, the average Reynolds numbers were kept to be 500, 1500, 2500, and 4500 . With the increase of the Reynolds number ratio at outlets $\left(\operatorname{Re}_{\mathrm{N} / \mathrm{E}}\right)$, the mixing becomes better at the north outlet, but worse at the east outlet. This is because, the inlet flow rates are equal, which flow together towards the north outlet and largely blocked the water flow from the west inlet to the east outlet, when the north outlet Reynolds number is greater than the east outlet Reynolds number (i.e., $\operatorname{Re}_{\mathrm{N} / \mathrm{E}}>1$ ). The average Reynolds number has almost no effect on the mixing degree when $\mathrm{Re}_{\mathrm{N} / \mathrm{E}}$ increases above 1.5. Because when $\mathrm{Re}_{\mathrm{N} / \mathrm{E}}$ increases over 1.5, the two outflows have a large flow rate difference, and the Reynolds number ratio of outflows $\left(\mathrm{Re}_{\mathrm{N} / \mathrm{E}}\right)$ is the primary factor to govern the mixing behavior instead of the average Reynolds number. When $\mathrm{Re}_{\mathrm{N} / \mathrm{E}}$ is about 1 , the average Reynolds number has an obvious impact on mixing, which is also presented in Figure 2.

3.4. Influence of Dimensionless Connecting Pipe Lengths $(L / D)$ on Double-Tee Junctions. The influence of the average
Reynolds number and dimensionless connecting pipe length on mixing at the double-Tee junction with equal pipe size (DN25) is shown in Figure 8. It appears that the dimensionless connecting pipe length $(L / D)$ can significantly affect the mixing ratio; mixing at double-Tee junction becomes better with the increase of $L / D$. This is because the long connecting pipe length provides more mixing space and time for the water flow mixing. Yet, at large $L / D$ values, the influence of the average Reynolds number on mixing is little evident. The average Reynolds number is not the determined factor on mixing for double-Tee junctions.

3.5. Influence of Reynolds Number Ratio at Outlets $\left(R e_{N / E}\right)$ on Double-Tee Junction. Yu et al. [13] found that the Reynolds number ratio of outflows $\left(\mathrm{Re}_{\mathrm{N} / \mathrm{E}}\right)$ will influence the mixing ratio on double-Tee junctions at high Reynolds numbers $(\operatorname{Re}>50000)$. To understand the effect of Reynolds number ratio of outflows $\left(\mathrm{Re}_{\mathrm{N} / \mathrm{E}}\right)$ on doubleTee junction at low Reynolds numbers $(\operatorname{Re}<10000)$, a series of experiments $(L / D=2.5,5.0,7.0$, and 10.0) have been carried out, and the results are shown in Figure 9. The experimental result of $L / D=2.5$ is shown in 


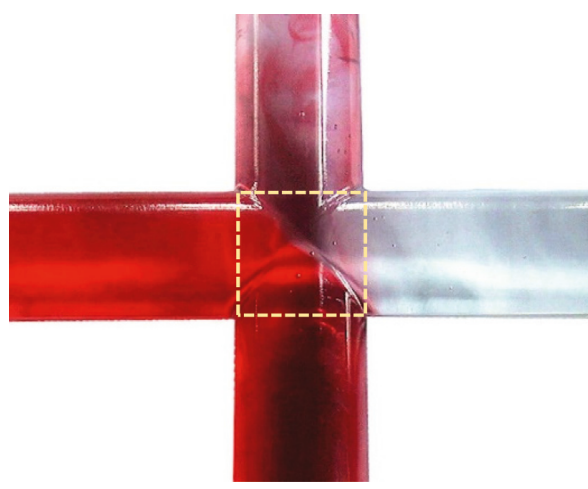

(a)

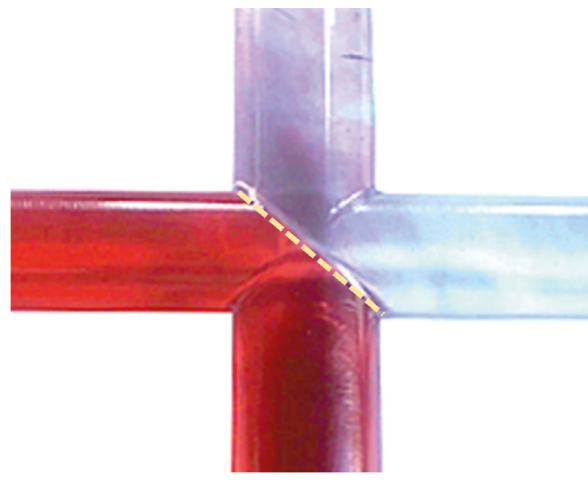

(c)

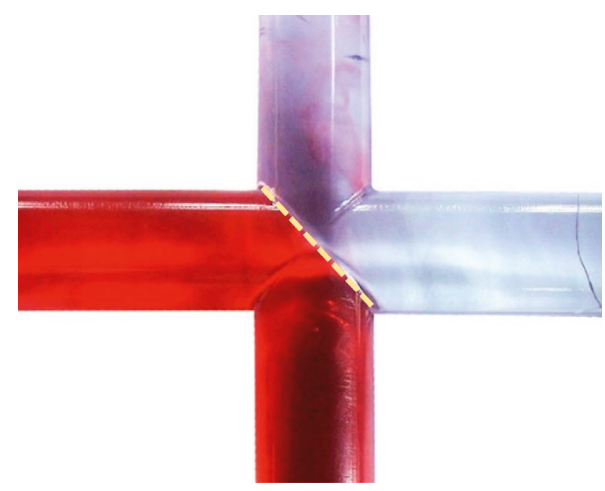

(b)

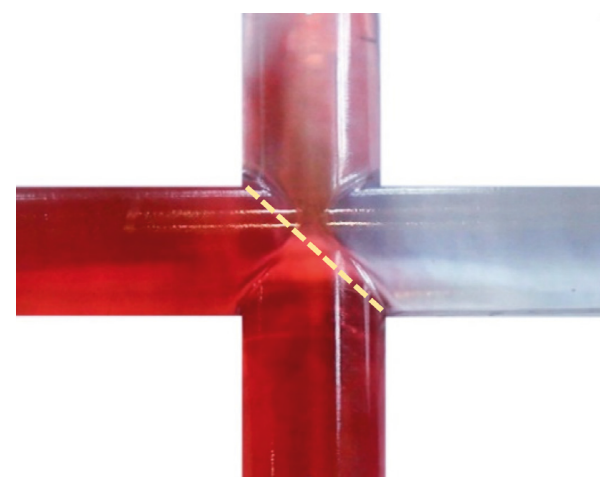

(d)

FiguRE 5: Junction mixing pictures under varied average Reynolds number. (a) $\operatorname{Re}_{\mathrm{ave}}=500 ;$ (b) $\operatorname{Re}_{\mathrm{ave}}=1000 ;(\mathrm{c}) \mathrm{Re}_{\mathrm{ave}}=1500$; (d) $\operatorname{Re}_{\text {ave }}=3000$.

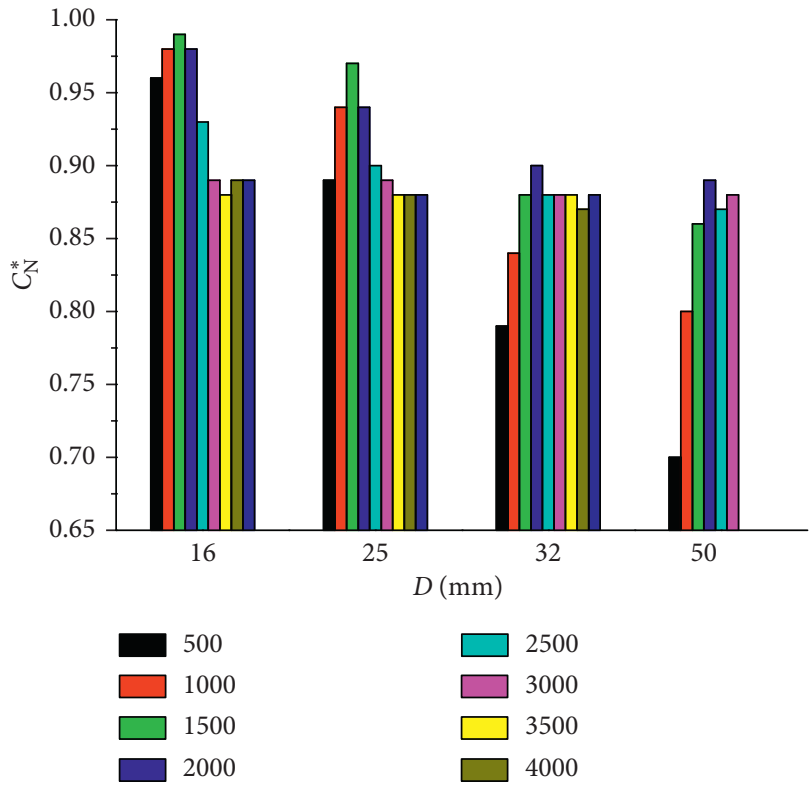

FIGURE 6: Normalized north outlet concentration $C_{\mathrm{N}}^{*}$ versus pipe diameters $D$ under $\operatorname{Re}_{\text {ave }}=500 \sim 5000$ at cross junction.

Figure 9(a). This is the case close to the cross junction, for which, the average Reynolds number has an influence on mixing when $\mathrm{Re}_{\mathrm{N} / \mathrm{E}}$ and not obviously for $\mathrm{Re}_{\mathrm{N} / \mathrm{E}}<1$. The influence of Reynolds number ratio on mixing is similar

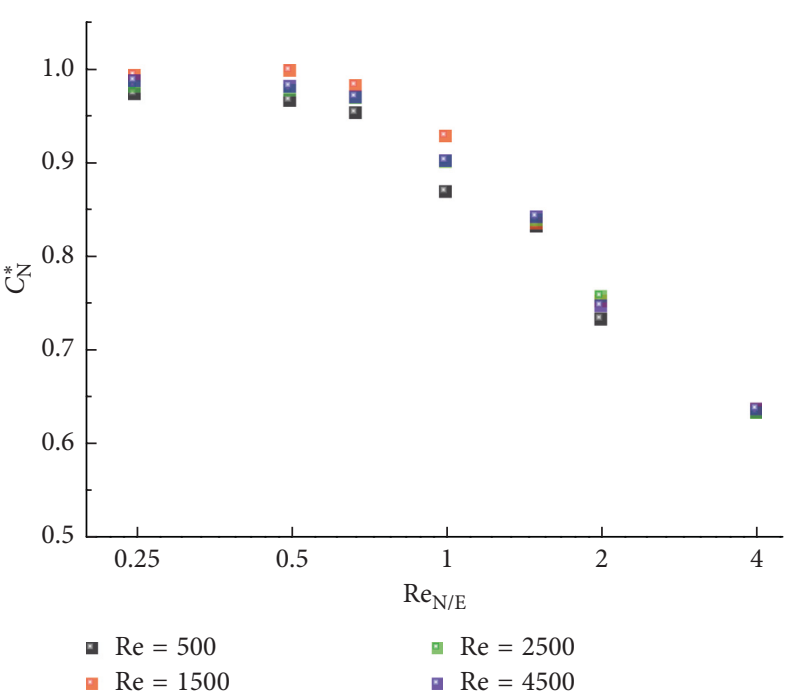

Figure 7: Normalized north outlet concentration $C_{\mathrm{N}}^{*}$ under varied $\operatorname{Re}_{\mathrm{N} / \mathrm{E}}$ at cross junction.

with cross junction but smaller. From Figures 9(b)-9(c), when $L / D=5.0 \sim 10.0$, the influences of the Reynolds number ratios of outflows $\left(\mathrm{Re}_{\mathrm{N} / \mathrm{E}}\right)$ and the average Reynolds number are weakened from $L / D=5.0$ to 10.0 , especially, the mixing for $L / D=10.0$, is close to perfect mixing. 


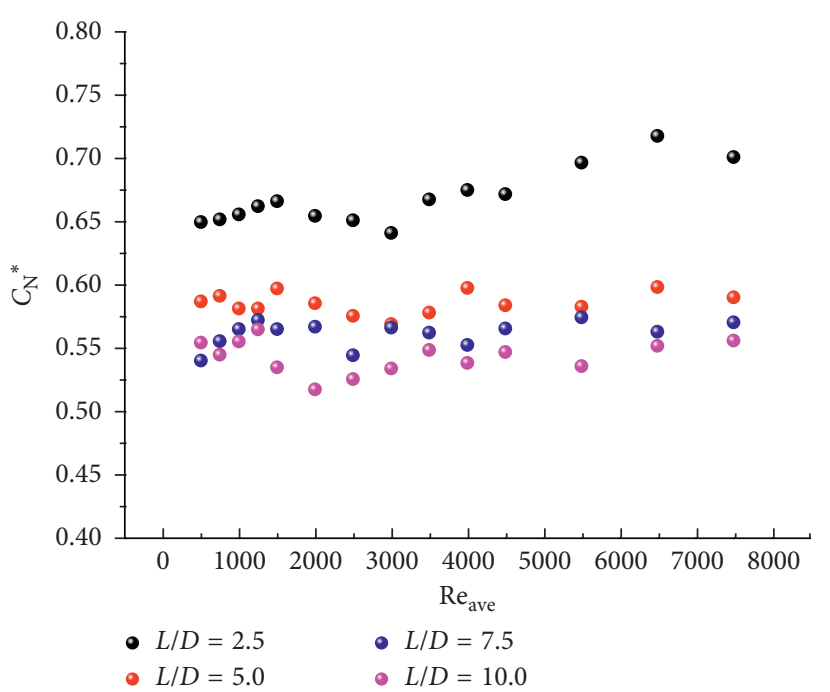

FIgURe 8: Normalized north outlet concentration $C_{\mathrm{N}}^{*}$ with different $L / D$ for varied average Reynolds number at double-Tee junction.

3.6. Comparison with Previous Studies. Austin et al. [10] only showed the mixing result on a cross junction with $16 \mathrm{~mm}$ inner diameter; hence, a comparison with our experimental result with $16 \mathrm{~mm}$ inner diameter is shown in Figure 10. When $\operatorname{Re}>3,000$, the overall trend of the two curves is close. When $1500<\operatorname{Re}<3000$, these two curves show the same trend that the mixing enhances with the increase of the Reynolds number. The biggest difference appears when $\operatorname{Re}<1500$. For the curve of $16 \mathrm{~mm}$ inner diameter, because of the experimental condition limit of the smallest $\mathrm{Re}=500$, the descent stage of the curve when $\operatorname{Re}<500$ is lost in Figure 10. However, we can infer that there must be a descent stage from $\operatorname{Re}=500$ to $\operatorname{Re}=0$. This tendency can be found for the DN50, DN32, and DN25 junction, as shown in Figure 3. Because the smallest Re in Austin et al. [10] is 700, it is not strange that the descent stage is not presented in their mixing curve.

Moreover, the geometries of the two junctions used in these two experiments are different. This study uses an integrated manufacturing Plexiglass junction shown in Figure 11. The inner surface of the junction is smoother than that of Austin et al. [10]. Figure 12 shows the detail of the experimental junction used by Austin et al. [10]. The junction is made by combining a four-way connection and four pipe legs. There is a small obstacle in the connecting location, which will change the flow regime locally. It has a significant influence in mixing, especially when the flow regime is laminar flow or transitional flow. That is to say, the junction of Austin et al. [10] has better mixing than this study for the same Reynolds number because of the enhanced disturbance by the junction of Austin et al. [10]. Figure 10 supports this inference when $1000<\operatorname{Re}<4000$.

The diameter of the pipe has a great influence on the mixing ratio when the $\operatorname{Re}<3000$. It can be seen from Figure 3 that when the Reynolds number is between 500 and 1500, the larger the pipe diameter, the better the mixing at the same Reynolds number. The experimental results of the junction with $16 \mathrm{~mm}$ inner diameter are similar to those of Austin et al. [10]. The pipe diameter determines the size of the mixing zone. When the flow rate is low and the flow state is laminar, the mixing time dominates the junction mixing instead of turbulent diffusion. When the Reynolds number increases, the flow rate increases, the mixing time decreases, and the degree of mixing is deteriorated. Moreover, when the Reynolds number increases and the flow state approaches the transitional flow, the influence of the turbulent diffusion becomes larger and exceeds the effect of the mixing time. Therefore, the experimental results with a diameter bigger than $25 \mathrm{~mm}$ in this paper appear as a convex curve in the interval of 500 to 1500 . On the other hand, when $\mathrm{Re} \longrightarrow 0$, molecular diffusion dominates the mixing, and sufficient mixing time causes the mixing to be complete.

\section{Conclusions}

Solute mixing phenomena under laminar and transitional flow conditions were investigated at cross and double-Tee junctions. These physical configurations and flow conditions prevail at small water demand areas, suburbs, mostly in perimeters of a water distribution system (WDS). Thus, study of solute mixing of the laminar and transitional flow can be important to the junction mixing model, particularly for water quality simulations.

For the cross junction, $C_{\mathrm{N}}^{*}$ versus $\mathrm{Re}_{\mathrm{ave}}$ relationship can be characterized in three hydraulic regions. Under $\operatorname{Re}<1500$ or laminar flow, mixing decreases as the Reynolds number increases. In transitional flow $(500<\operatorname{Re}<3000)$, mixing increases as the Reynolds number increases; and lastly in turbulent flow of Re $>3000$, the degree of mixing is constant invariant of flow variations. Mixing at cross junction of a large diameter is better than that of a small diameter when $\operatorname{Re}<3000$. Under this condition, mixing becomes better at the north outlet, but worse at the east outlet, with the increase of the Reynolds number ratio at outlets $\left(\mathrm{Re}_{\mathrm{N} / \mathrm{E}}\right)$.

For the double-Tee junction, the influence of the average Reynolds number on junction mixing is less prevalent than for the cross junction under laminar and transitional flow conditions. Mixing at double-Tee junction becomes better with the increase of $L / D$. At higher values $>5.0, L / D$ becomes a determined factor on mixing, while Reynolds number ratios of outflows $\left(\operatorname{Re}_{\mathrm{N} / \mathrm{E}}\right)$ and the average Reynolds number become less important. The longer connecting pipe length provides more mixing space and time for the water flows mixing.

In this study, experimental research is used for understanding the junction mixing under laminar and transitional flow. Different pipe diameters and Reynolds number ratios of outflows are considered in this paper. The geometry characteristic difference of the junctions used in this study and Austin et al. [10] causes the slight difference of these results. The diameter of the pipe has a great influence on the mixing ratio when $\operatorname{Re}<3000$. The lack of experimental data of Re below 700 and only the $16 \mathrm{~mm}$ diameter junctions used in Austin et al. [10] caused the mixing curve difference. 

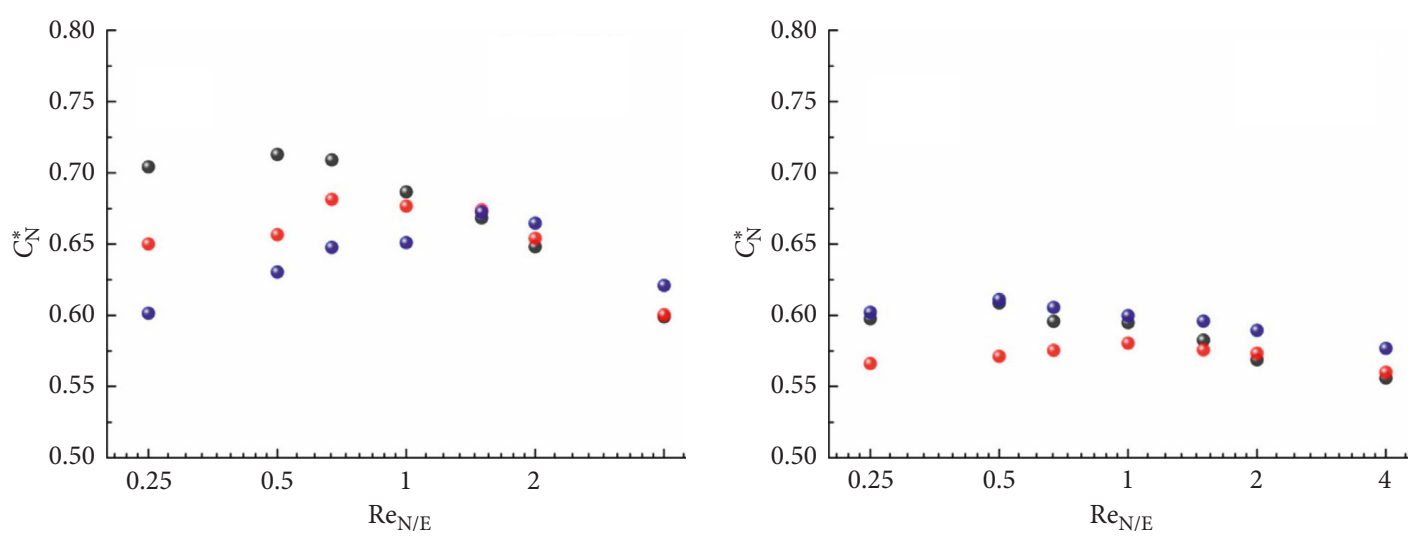

- $\mathrm{Re}=4500$

- $\mathrm{Re}=4500$

- $\mathrm{Re}=2500$

- $\mathrm{Re}=2500$

- $\mathrm{Re}=1500$

(a)

(b)
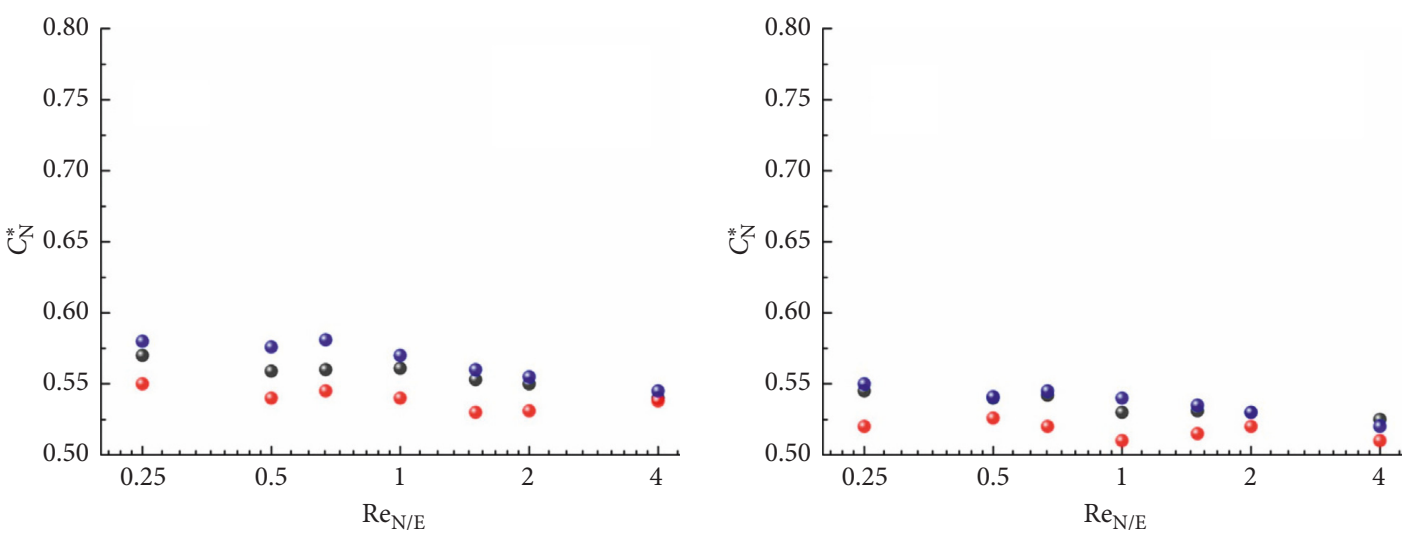

- $\mathrm{Re}=4500$

- $\mathrm{Re}=4500$

- $\mathrm{Re}=2500$

- $\mathrm{Re}=2500$

- $\mathrm{Re}=1500$

(c)

(d)

Figure 9: Dimensionless concentration $C_{\mathrm{N}}^{*}$ versus Reynolds number ratios of outflows $\mathrm{Re}_{\mathrm{N} / \mathrm{E}}$ at double-Tee junctions: (a) $L / D=2.5$; (b) $L / D=5.0$; (c) $L / D=7.5$; (d) $L / D=10.0$.

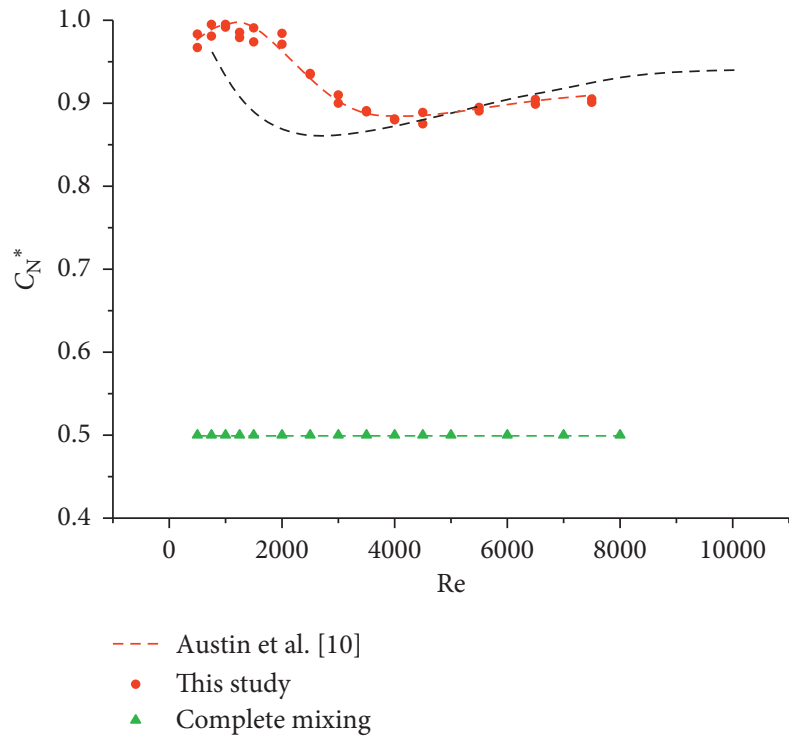

Figure 10: Comparison of experimental results between Austin et al. [10] and this study. 


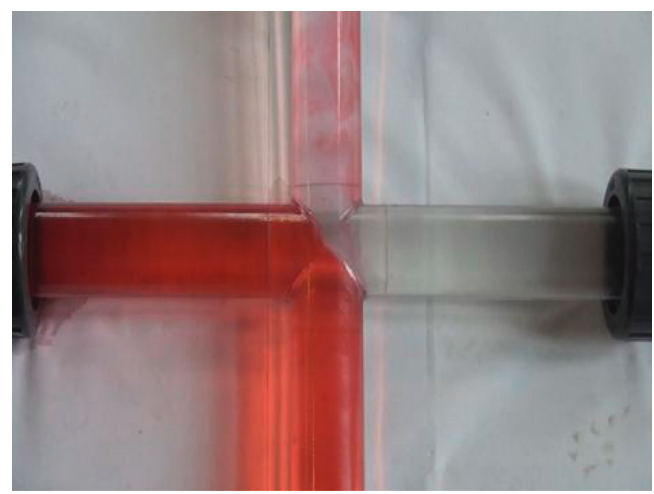

(a)

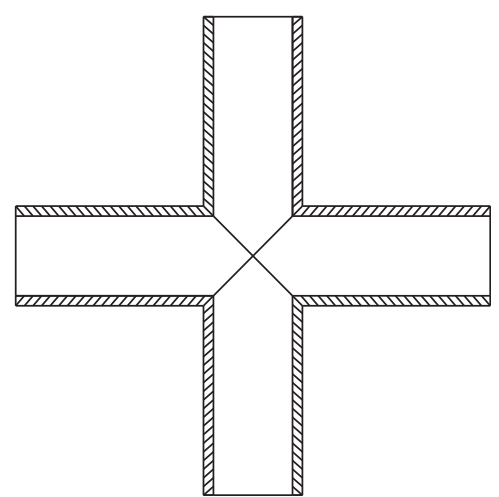

(b)

Figure 11: The geometry of joint used in this study.

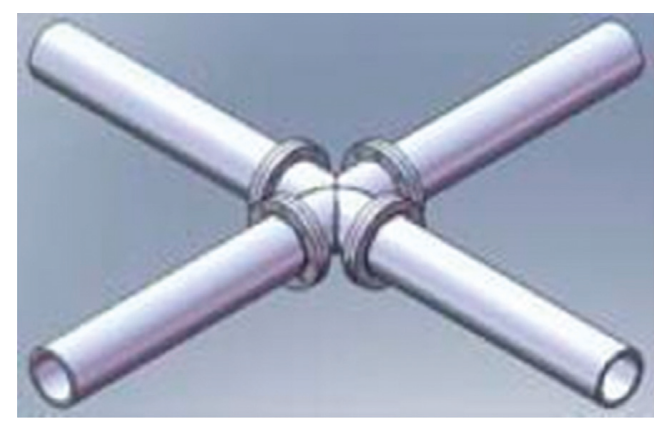

(a)

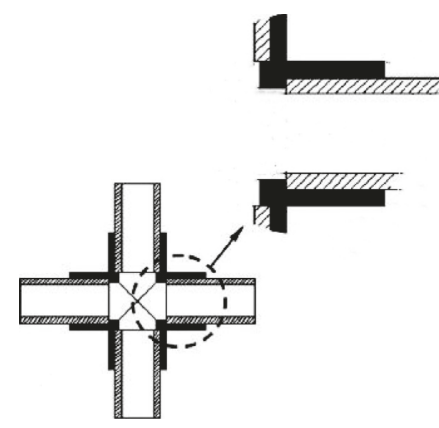

(b)

FIgURE 12: The geometry of joint used by Austin et al. [10].

Future work should be focused on the mechanism of the junction mixing, especially under laminar and transitional flow.

\section{Data Availability}

The experimental data used to support the findings of this study are included within the article.

\section{Disclosure}

Although not directly funded by U.S. EPA, this paper has also been subjected to the Agency's administrative review and has been approved for external publication.

\section{Conflicts of Interest}

The authors declare that they have no conflicts of interest.

\section{Acknowledgments}

This research was funded by the National Key Research and Development Program of China (no. 2016YFC0400600), Science and Technology Program of Zhejiang Province (nos. 2017C33174 and 2015C33007), National Natural Science Foundation of China (nos. 51208457 and
51478417), and Fundamental Research Funds for the Central Universities (no. 2019FZA4019).

\section{Supplementary Materials}

These three videos display the mixing of a cross junction with $50 \mathrm{~mm}$ pipe diameter. The video named as " $\mathrm{Re}=500$ " shows the mixing of the junction when the Reynolds number of the four pipes is 500. Similarly, the other two videos show mixing when the Reynolds number of the four pipes is 1500 and 2500, respectively. In the videos, the pipe on the right and the bottom are the pipes with inflow, and the pipes on the left and the upper are the pipes with outflow. These three videos support our mixing result (Figure 3 ) in this paper- "first increase, then decrease, and then slight increase." (Supplementary Materials)

\section{References}

[1] L. Rossman, EPANET-Use's Manual, US EPA, Cincinnati, OH, USA, 2000.

[2] J. B. Burkhardt, J. Szabo, S. Klosterman, J. Hall, and R. Murray, "Modeling fate and transport of arsenic in a chlorinated distribution system," Environmental Modelling and Software, vol. 93, pp. 322-331, 2017.

[3] H. Mala-Jetmarova, N. Sultanova, and D. Savic, "Lost in optimisation of water distribution systems? A literature 
review of system operation," Environmental Modelling and Software, vol. 93, pp. 209-254, 2017.

[4] W. M. Grayman, L. A. Rossman, and E. E. Geldreich, "Water quality," in Water Distribution Systems Handbook, L. W. Mays, Ed., McGraw-Hill, New York, NY, USA, 1999.

[5] R. G. Austin, B. V. B. Waanders, S. McKenna, and C. Y. Choi, "Mixing at cross junctions in water distribution systems. II: experimental study," Journal of Water Resources Planning and Management, vol. 134, no. 3, pp. 295-302, 2008.

[6] C. Y. Choi, J. Y. Shen, and R. G. Austin, "Development of a comprehensive solute mixing model (AZRED) for double-tee, cross, and wye junctions," in Proceedings of the 10th Annual Water Distribution Systems Analysis Symposium, Kruger National Park, South Africa, August 2008.

[7] C. K. Ho, L. Orear, J. L. Wright, and S. A. McKenna, "Contaminant mixing at pipe joints: comparison between laboratory flow experiments and computational fluid dynamics models," in Proceedings of the 8th Annual Water Distribution System Analysis Symposium, Cincinnati, OH, USA, August 2006.

[8] S. W. Choi, "High-fidelity simulation of the influence of local geometry on mixing in crosses in water distribution systems," in Proceedings of the 9th Annual Water Distribution Systems Analysis Symposium, ASCE/EWRI, Tampa, Florida, USA, 2007.

[9] S. A. Mckenna, L. Orear, and J. Wright, "Experimental determination of solute mixing in pipe joints," in Proceedings of the ASCE 2007 World Environmental and Water Resources Congress, Tampa, FL, USA, 2007.

[10] R. G. Austin, P. Romero-Gomez, and C. Y. Choi, "Transport phenomena at intersections at low Reynolds numbers," in Proceedings of the World Environmental and Water Resources Congress 2007: Restoring Our Natural Habitat, Tampa, FL, USA, May 2007.

[11] P. Romero-Gomez, C. K. Ho, and C. Y. Choi, "Mixing at cross junctions in water distribution systems. I: numerical study," Journal of Water Resources Planning and Management, vol. 134, no. 3, pp. 285-294, 2008.

[12] T. C. Yu, Y. Shao, and C. Shen, "Mixing at cross joints with different pipe sizes in water distribution systems," Journal of Water Resources Planning and Management, vol. 140, no. 5, pp. 658-665, 2014.

[13] T. Yu, L. Tao, Y. Shao, and T. Zhang, "Experimental study of solute mixing at double-tee junctions in water distribution systems," Water Science and Technology: Water Supply, vol. 15, no. 3, pp. 474-482, 2014.

[14] Y. Shao, Y. Jeffrey Yang, L. Jiang, T. Yu, and C. Shen, "Experimental testing and modeling analysis of solute mixing at water distribution pipe junctions," Water Research, vol. 56, pp. 133-147, 2014.

[15] T. Yu, H. Qiu, J. Yang, Y. Shao, and L. Tao, "Mixing at doubletee junctions with unequal pipe sizes in water distribution systems," Water Science and Technology: Water Supply, vol. 16, no. 6, pp. 1595-1602, 2016.

[16] I. Song, P. Romero-Gomez, M. A. Andrade, M. Mondaca, and C. Y. Choi, "Mixing at junctions in water distribution systems: an experimental study," Urban Water Journal, vol. 15, no. 1, pp. 32-38, 2018.

[17] Y. Y. Zhao, Y. J. Yang, Y. Shao, Y. Lee, and T. Q. Zhang, "Demand-driven spatiotemporal variations of flow hydraulics and water age by comparative modeling analysis of distribution network," Journal of Water Resources Planning and Management, vol. 144, no. 12, article 04018074, 2018.
[18] P. Romero-Gomez, C. Y. Choi, B. van Bloemen Waanders, and S. A. McKenna, "Transport phenomena at intersections of pressurized pipe systems," in Proceedings of the 8th Annual Water Distribution System Analysis Symposium, Cincinnati, OH, USA, August 2006. 


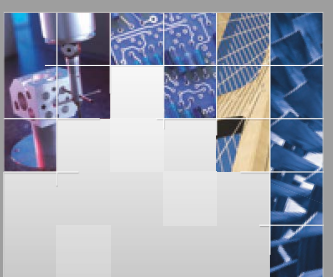

\section{Enfincering}
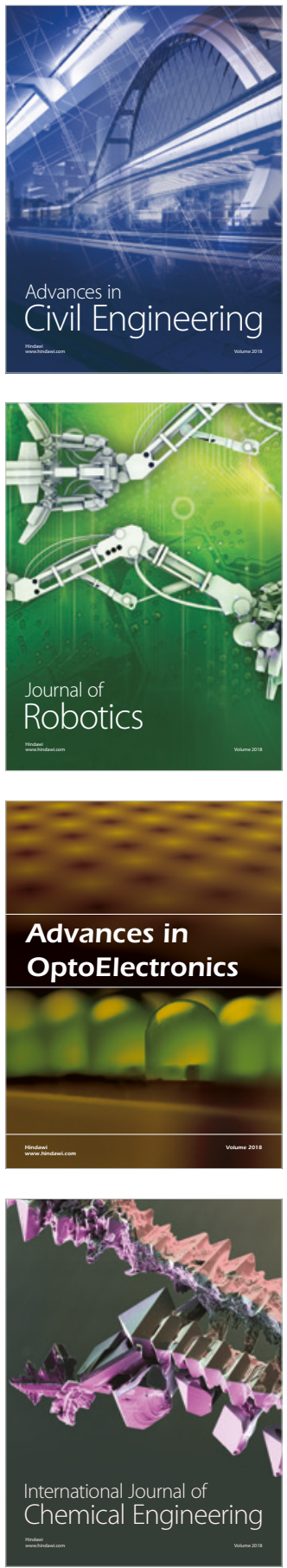

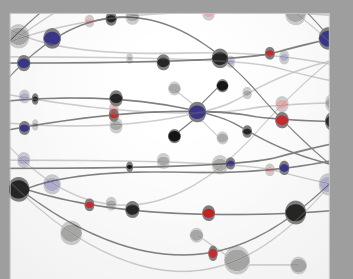

\section{Rotating \\ Machinery}

The Scientific World Journal

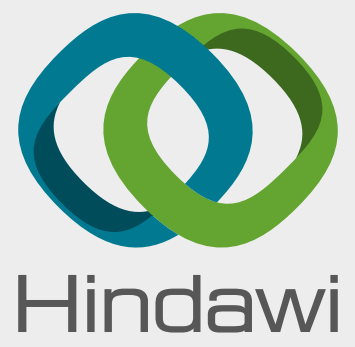

Submit your manuscripts at

www.hindawi.com
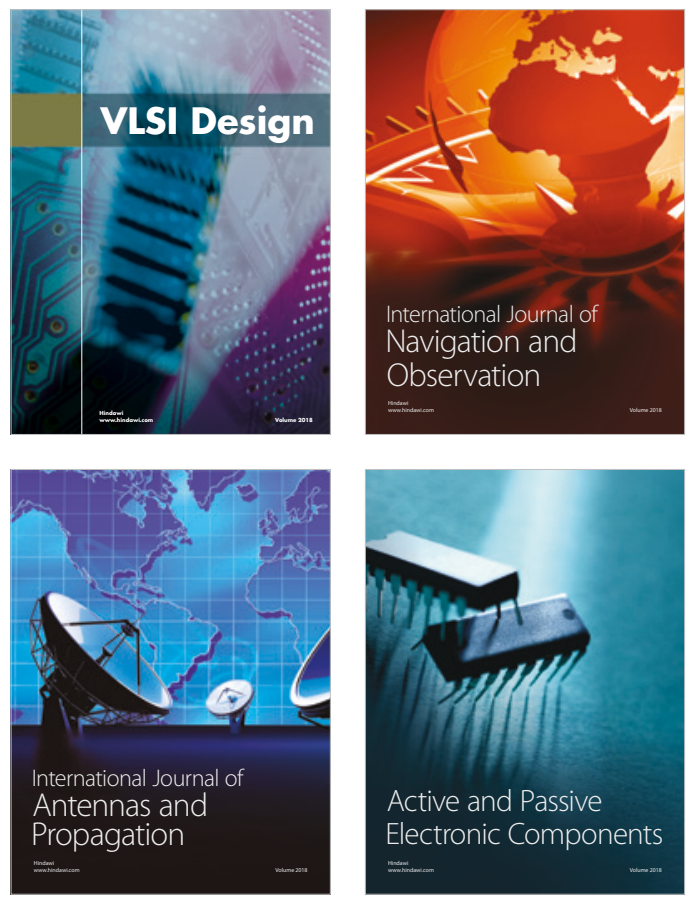
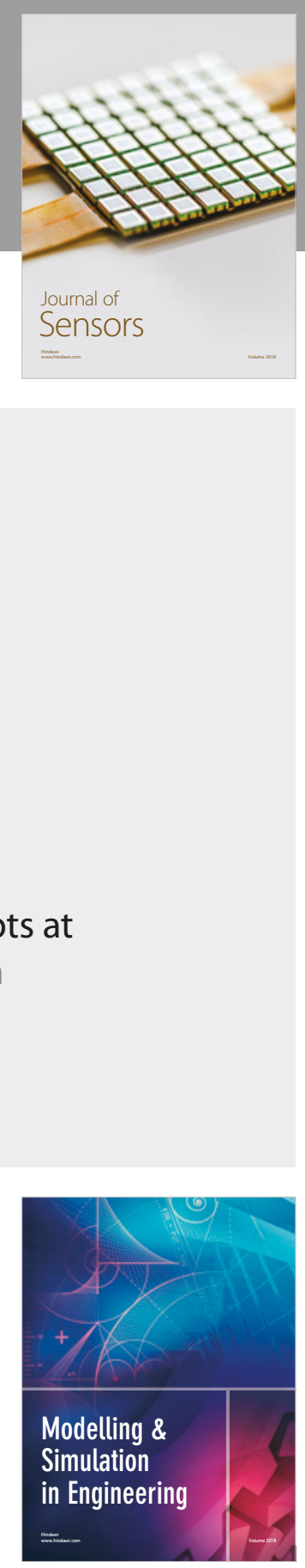

\section{Advances \\ Multimedia}
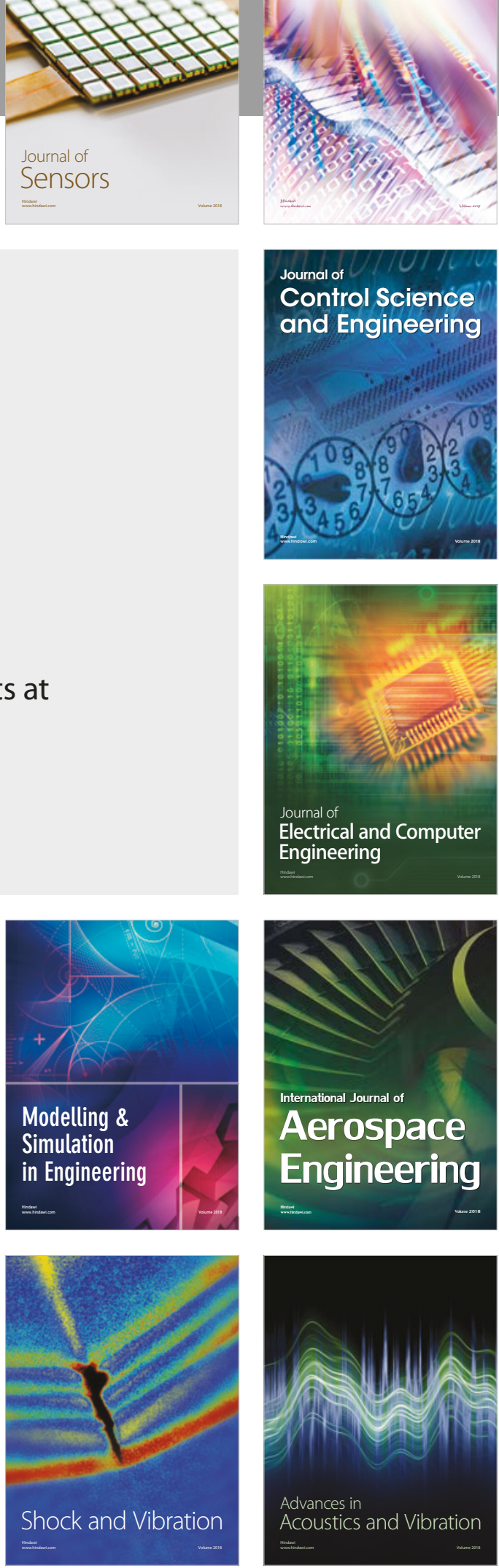